\title{
Centros de desarrollo empresarial zonal: experiencias significativas de desarrollo sostenible en Medellín*
}

\author{
Astelio Silvera Sarmiento**, Albert Corredor Bustamante ${ }^{\star * \star}$, Haydeé Bermeo Duque ${ }^{\star \star * *}$, \\ Carlos Ramírez Betancur ${ }^{* * * *}$, Nadine Van Son ${ }^{* * * * *}$
}

\begin{abstract}
Resumen
Introducción. Este artículo se elabora a partir del estudio de evaluación de impacto del programa de los Centros de Desarrollo Empresarial Zonal (CEDEZO). Objetivo. Conocer los resultados y la prospección del programa CEDEZO en sus primeros seis (6) años de funcionamiento, a partir de su incidencia en la superación del fenómeno de la violencia en la ciudad de Medellín durante la década de 1990. Materiales y métodos. Se realizó un estudio cualitativo en prospectiva estratégica a procesos de capacitación, charla y asesoría empresariales, sensibilización, gestión interinstitucional e intervención por barrios a un total de 552 participantes. Resultados. Los diagnósticos elaborados por las entidades públicas hacen evidente una profundización de las diferencias económicas y sociales territoriales en la ciudad, y una población cada vez más creciente y excluida de las dinámicas económicas y de las oportunidades de empleo, ingresos y créditos. La exclusión profundiza la informalidad, un problema estructural en el país, e incrementa los niveles de pobreza. Se registró en el año 2002 un nivel de $60 \%$ de su población por debajo de la línea de pobreza y una tasa de informalidad de $54,6 \%$ en ese mismo año. Conclusiones. Se hace necesaria una estrategia que fomente el desarrollo y fortalecimiento del tejido
\end{abstract}

empresarial competitivo para generar una cultura del emprendimiento, la prospectiva y la actitud de empresarismo de los ciudadanos.

Palabras clave: MIPYMES, emprendimiento, fortalecimiento empresarial, prospectiva.

\section{Zonal entrepreneurial development centers: significant experiences of sustainable development in Medellín}

\begin{abstract}
Introduction. This article is made starting from the impact evaluation study of the CEDEZO program (Centros de desarrollo empresarial zonal, Zonal Entrepreneurial Development Centers). Objective. See the results and the prospection of the CEDEZO program in its first six years of functioning, and its role in getting over the 1990's violence of Medellín. Materials and methods. A qualitative study in strategic prospective to training, speaking and advisory about entrepreneurial subjects, sensitization, inter-institutional management and intervention in neighborhoods was made with 552 participants. Results. The diagnosis made by public entities demonstrate deeper economic and social differences in the territories of the city,
\end{abstract}

\footnotetext{
* Artículo de investigación resultado de investigación del Grupos Gisela de la Corporación Universitaria Americana, en colaboración con los grupos de investigación TES y Derecho Justicia y Estado Social de Derecho y la cooperación con el Master in Management of Innovation de la Rotterdam School of Management (Rotterdam School of Management).

** Abogado, magíster en Educación. Candidato a Doctor en Ciencias de la Educación. Vicerrector de Investigaciones Corporación Universitaria Americana. mail: asilvera@coruniamericana.edu.co

*** MBA Administration, CENSA College (Estados Unidos). Administración de Empresas, EAFIT. Vicerrector de Extension, proyección social e internacionalizacion Corporacion Universitaria Americana . mail: vicerrectorext@coruniamericana.edu.co

**** Economista de la Universidad Central (Bogotá). Especialista en Docencia Universitaria de la Universidad Cooperativa de Colombia y en Literatura: Producción de Textos e Hipertextos de la Universidad Pontificia Bolivariana. Candidata a magíster en Educación de la Universidad Pontificia Bolivariana. Docente Investigadora del Grupo GISELA. Corporación Universitaria Americana. mail: hbermeo@ americana.edu.co

**** Docente de medio tiempo Corporación Universitaria Americana; docente de cátedra UPB, Miembro Grupo 180 Responsabilidad Social, coinvestigador, economista, especialista en Gerencia, magíster en Dirección de Mercados

****** BSc International Business Administration de la Rotterdam School of Management, Erasmus University Rotterdam y candidata a Magister en MSc Master in Management of Innovation de la Rotterdam School of Management, Erasmus University Rotterdam, políglota y docente internacional del programa de Negocios Internacionales de la Corporación Universitaria Americana, sede Barranquilla
}

Autor para correspondencia: Astelio Silvera Sarmiento, email: asilvera@coruniamericana.edu.co Artículo Recibido: 10/04/2016; Artículo Aprobado: 15/11/2016 
and also shows a population that grows in terms of economical dynamics, lack of employment opportunities, income and credits. That exclusion deepens informality, a structural Colombian problem, and increases the poverty levels. In 2002, $60 \%$ of the population was registered as living below the poverty line and an informality rate of $54,6 \%$. Conclusions. It is necessary to propose a strategy that boosts the development and the strengthening of the competitive businesses to generate an entrepreneurship culture, the prospective and the entrepreneurial attitude among the citizens.

Key words: SMB's, entrepreneurship, businesses strengthening, prospective.

\section{Centros de desenvolvimento empresarial zonal: experiências significativas de desenvolvimento sustentável em Medellín}

\section{Resumo}

Introdução. Este artículo se elabora a partir do estudo de avaliação de impacto do programa dos Centros de Desenvolvimento Empresarial Zonal (CEDEZO). Objetivo. Conhecer os resultados e a prospecção do programa CEDEZO no seus primeiros seis (6) anos de funcionamento, a partir de sua incidência na superação do fenômeno da violência na cidade de Medellín durante a década de 1990. Materiais e métodos. Se realizou um estudo qualitativo em prospectiva estratégica a processos de capacitação, conversa e assessoria empresariais, sensibilização, gestão interinstitucional e intervenção por bairros a um total de 552 participantes. Resultados. Os diagnósticos elaborados pelas entidades públicas fazem evidente um aprofundamento das diferenças econômicas e sociais territoriais na cidade, e uma população cada vez mais crescente e excluída das dinâmicas econômicas e das oportunidades de emprego, ingressos e créditos. A exclusão aprofunda a informalidade, um problema estrutural no país, e incrementa os níveis de pobreza. Se registrou em 2002 um nível de $60 \%$ de sua população por baixo da linha de pobreza e uma taxa de informalidade de 54,6 \% nesse mesmo ano. Conclusões. Se faz necessária uma estratégia que fomente o desenvolvimento e fortalecimento do tecido empresarial competitivo para gerar uma cultura do empreendimento, a prospectiva e a atitude de empresário dos cidadãos.

Palavras chave: MIPYMES, empreendimento, fortalecimento empresarial, prospectiva.

\section{Introducción}

Un programa que pretende superar las situaciones de adversidad es un indicador de compromiso y responsabilidad del Estado frente a sus ciudadanos, para lo cual se hace imperativo contar con las herramientas de análisis e impacto suficientes para promover una cultura del emprendimiento o cultura $\mathrm{E}$, que apoye la generación de empleo e ingresos mediante el fortalecimiento empresarial sostenible. El surgimiento de un contexto interinstitucional entre los Concursos de Planes de Negocios, Capital Semilla, Banco de los Pobres, Red Microcrédito, Medellín mi Empresa favorecen su consolidación en el año 2005 (Alcaldía de Medellín, 2011).

Los Centros de Desarrollo Empresarial son un programa integral de servicios empresariales, creado con el fin de brindarles a los microempresarios de la ciudad servicios y herramientas de acompañamiento $y$ fortalecimiento en las áreas empresariales. La misión del programa es dinamizar el desarrollo local generando vocaciones productivas y oportunidades de mercado identificadas para cada subsector (Consejo de Medellín, 2014). Su implementación en pro del fortalecimiento de la capacidad empresarial, en los niveles sociales de ingreso más bajo con el apoyo y trabajo conjunto de estamentos públicos y privados de la ciudad, incide en la calidad de vida y patrimonio habitable para población vulnerable (Escalante, 2012). Esta iniciativa cuenta con la cooperación de entidades tales como la Alcaldía de Medellín, PROANTIOQUIA, ANDI, Cámara de Comercio de Medellín, ACOPI, Microempresas de Antioquia, FENALCO, Interactuar, Comfama, Comfenalco, SENA, EAFIT y ESUMER.

\section{CONTEXTO}

El programa actualmente cuenta con los centros que se muestran en la tabla 1. 
Tabla 1. Listado de CEDEZO Medellín 2011

\begin{tabular}{l|l}
\hline San Cristóbal & La Ladera \\
\hline Santo Domingo & Centro \\
\hline Moravia & Palmitas \\
\hline San Antonio de Prado & Alta Vista \\
\hline La Quintana & San Javier \\
\hline Santa Elena & Castilla \\
\hline Manrique & Centros Comerciales \\
\hline Belén & \\
\hline Fuente: Alcaldía de Medellín, 2015 &
\end{tabular}

\section{Definición de etapas del desarrollo de emprendimiento}

Ideas de negocio: etapa inicial de emprendimiento a elaborar el plan de negocio.

Idea en transición: el emprendimiento posee producto y cliente a escala mínima, es informal con un rendimiento de supervivencia y sin ubicación geográfica permanente.

Creación: inicio de negocio, acceso a crédito con capital semilla, ampliación de mercado con adecuación de espacio permanente.

Fortalecimiento: 1 año 1 empleo adicional al propio, formalización inicial (Cámara de Comercio, RUT), ingreso promedio estable (Montoya, 2011).
La evaluación de requerimientos en desarrollo de emprendimiento consta de los siguientes elementos:

1. Identificación de potencialidades y necesidades del tejido empresarial.

2. Identificación de recursos, equipos e institucionalidad para el fortalecimiento empresarial.

3. Elaboración del plan de intervención y vinculación de operadores institucionales

4. Identificación y seguimiento de impacto en el territorio

\section{Las variables de los factores interno y} externo (tabla 2)

Tabla 2. Factores internos y externos

\begin{tabular}{l|l}
\hline Infraestructura y Equipos & Alianza Internacional \\
\hline Capital Humano & Política Pública - Normatividad \\
\hline Recurso Financiero & Cultura de Emprendimiento \\
\hline Servicios CEDEZO & Seguridad Territorial \\
\hline Tecnología & Interinstitucionalidad \\
\hline Cobertura & Voluntad Política \\
\hline
\end{tabular}

Fuente: Alcaldía de Medellín, 2015

\section{PROSPECTIVA}

La prospectiva esencialmente se define en las siguientes preguntas (Giget, 1998):

¿Qué puede ocurrir? (Prospectiva)

$$
\begin{array}{ll}
\text { ¿Qué puedo hacer? } & \begin{array}{l}
\text { (Prospectiva } \\
\text { estratégica) }
\end{array} \\
\text { ¿Qué voy a hacer? } & \text { (Estrategia) } \\
\text { ¿Cómo voy a hacerlo? } & \begin{array}{l}
\text { (Planificación } \\
\text { estratégica) }
\end{array}
\end{array}
$$


La prospectiva es una disciplina de reciente aparición en el mundo (Godet, De la anticipación a la acción. Manual de estrategia y prospectiva, 1993); si bien este campo de saber y de acción ha existido desde la antigüedad en sentido de mística, y se desarrolló hasta entrado el siglo XX como ciencia ficción, hoy se conoce como ciencia que ayuda a comprender y visualizar el futuro para influir en él, mediante los estudios participativos (Serbolov, 2010).

Diversas escuelas con distintos métodos y enfoques han caracterizado una historia de la prospectiva en la que, además de construir un conocimiento sólido para el diseño y gestión de las políticas públicas y el desarrollo territorial y comunitario, se ha propendido por contribuir con la Administración Pública y privada, especialmente en la articulación con el pensamiento estratégico (Medina \& Ortegón, 2006).

El vínculo de la prospectiva con la planeación territorial ha significado un avance tanto para el pensamiento estratégico en el contexto de la gobernabilidad como para la gestión pública. Podría decirse que si bien la prospectiva puede utilizarse en muchas disciplinas "dos usos serán particularmente útiles para el científico social de la política: el pensamiento prospectivo y la planeación prospectiva" (Baena, 2004).

La creciente incertidumbre, la amenaza del caos y el desorden, la contingencia producida por la velocidad del cambio y la ruptura de paradigmas, en especial en el campo de lo político, generan una serie de riesgos posibles de anticipar mediante la prospectiva (Arroyo, 2008). Así, con los estudios anticipatorios hemos podido buscar en el pensamiento sistémico prospectivo nuevas herramientas que permitan a las comunidades insertas en los territorios diseñar estrategias y adelantar acciones con gran sentido de pertinencia y coherencia, garantes de una mejor toma de decisiones, una pertinente formulación de políticas, estrategias y proyectos de cambio y transformación social justa y sostenible (Molina et. al. 2015; Garces \& Giraldo, 2013).

La prospectiva en la gestión territorial y en varias disciplinas se ha convertido en un campo de especialización e investigación al punto de permitir valiosos desarrollos metodológicos dignos de réplica (Burgoin, 2013).

Las mismas políticas públicas han apropiado los ejercicios prospectivos pues la alta incertidumbre de los sistemas sociales, políticos y culturales, así como ecológicos, exige recurrir a otras herramientas que contribuyan con la complementación del pensamiento lineal tan firmemente interiorizado en todos los campos del saber, en especial, en la gestión pública (Perrotti, 2014). De igual forma en la gestión territorial, cada día, se hace más visible la necesidad de consolidar un pensamiento estratégico que pueda imaginar el futuro, y revisitarlo para poder construirlo (Machado, 2014).

El futuro no existe, ni está escrito en ninguna parte; no obstante, uno de los padres de la prospectiva sostenía que el futuro puede ser comprendido como una realidad única o como una realidad múltiple que en sí son futuribles (Jouvenel, 1965); de esta manera el futuro tiene diversas alternativas, pero es preciso construirlo desde el presente, puesto que el pasado ya no existe, solo nos queda visualizar el futuro para vivirlo en el presente.

Los territorios y su tejido de organizaciones y sus actores podrán imponer tendencias en el presente solo si pueden imaginar el futuro $y$, obviamente, moldear su pensamiento y su voluntad de acción apropiadora para movilizarse hacia él, creándolo desde el presente (Silvera et. al, 2015).

La prospectiva en su práctica se vale de diversas herramientas que permiten la anticipación, la apropiación y la movilización. También se le considera como una forma de concebir el mundo más allá de los límites disciplinares; que exige el trabajo con los actores de cualquier territorio, sector, actividad u organización.

Se trata de buscar visiones compartidas de futuro que puedan ser aplicables en la gestión, involucrando la percepción de actores y el juicio de expertos. La prospectiva territorial tiene como tarea permitir la imaginación del futuro de manera participativa y consensuada; para ese efecto requiere de etapas y pasos que exigen 
un barrido de tendencias, la identificación de factores que generan el cambio, el estudio de la dinámica del sistema territorial y el comportamiento de las variables de alta influencia y dependencia, el reconocimiento del juego de los actores (Godet, 2007) que condicionan con sus intereses la vida del territorio $\mathrm{y}$, por último, la construcción de los escenarios alternativos de futuro que iluminan las estrategias y las acciones de la siguiente forma:

Juego de actores (Godet, 2007):

1. Dominantes: $>$ Influencia $<$ Dependencia

2. Dominados: <Influencia >Dependencia
3. Autónomos: <Influencia <Dependencia

4. Enlace: >Influencia >Dependencia

\section{Ábaco de Régnier}

Las variables críticas obtenidas provienen del análisis DOFA y luego se identifica, con un descriptor, la variable, y el color indica la puntuación, tal como se ve en la tabla 3 :

\section{Puntaje:}

1. Muy importante: Azul

2. Es importante: Verde

3. Medianamente importante: Amarillo

4. Poco importante: Rosado

Tabla 3. Descriptores de factores

\begin{tabular}{l|ll|l|ll}
\hline No. & \multicolumn{2}{|c|}{ Descriptor de Factores } & No. & \multicolumn{2}{|c}{ Descriptor de Factores Críticos } \\
\hline 1 & Político & FP & 1 & Político & P \\
\hline 2 & Económico & FE & 2 & Económico & E \\
\hline 3 & Social & FS & 3 & Social & S \\
\hline 4 & Institucional & FI & 4 & Institucional & I \\
\hline 5 & Tecnológico & FT & 5 & Tecnológico & T \\
\hline
\end{tabular}

\section{Metodología}

Las herramientas de prospectiva del programa (tabla 4) requieren diferentes técnicas, tanto cuantitativas como cualitativas. La prospectiva se ha convertido en la actualidad en una aliada para la toma de decisiones de hoy, pero pensadas a futuro, con base en los históricos y las tendencias que se presentan. En este orden de ideas, el análisis prospectivo del programa se hace a partir del análisis del futuro de los factores críticos identificados, apoyado en metodologías altamente reconocidas en el contexto mundial.

Tabla 4. Prospección para el programa

\begin{tabular}{|c|c|c|}
\hline Áreas & $\begin{array}{l}\text { Variables internas } \\
\text { Gestión servicio } \\
\text { Capital humano }\end{array}$ & $\begin{array}{l}\text { Variables externas } \\
\text { Ecosistema de emprendimiento }\end{array}$ \\
\hline Factor crítico & \multirow{5}{*}{\multicolumn{2}{|c|}{$\begin{array}{c}\text { Identificación } \\
\text { Variables clave del programa } \\
\text { Política pública } \\
\text { Construcción } \\
\text { Diseño de estrategias }\end{array}$}} \\
\hline Regnier & & \\
\hline Juego de actores & & \\
\hline Método de escenarios & & \\
\hline Opciones estratégicas & & \\
\hline
\end{tabular}

Fuente: análisis de los investigadores, 2015 


\section{Materiales y métodos}

Se retoma la condición ya expuesta con respecto a las herramientas utilizadas para definir la prospectiva de los centros, considerando fuentes primarias y secundarias, así:

1. Las encuestas aplicadas a los emprendedores y empresarios.

2. Las entrevistas a los expertos, tomando los elementos en común y las diferencias planteadas.

3. El análisis del ecosistema del emprendimiento.

4. La definición de variables tanto para el corto como para el largo plazo.
5. Los históricos y las tendencias del programa. Estos permiten medir las actitudes de un grupo frente a un tema determinado, y lo hace considerando desde lo más importante hasta lo menos importante.

Método de escenarios. Pretende representar los escenarios futuros a partir del análisis; se hace de acuerdo con la agrupación que se haga de las variables.

Instrumento. El formulario consta en total de 70 preguntas abiertas sub-divididas en factores internos y externos. La encuesta a 520 participantes se aplicó en los meses de septiembre y octubre de 2011. El muestreo es probabilístico estratificado por sedes con una confiabilidad del $90 \%$.

Tabla 5. Escala del instrumento cumplimiento de objetivos

\begin{tabular}{l|c|c}
\hline Nominal & Valor & Porcentaje \\
\hline No aplica (no se califica) no coloque calificación & & \\
\hline No cumple & 0 & 0 \\
\hline Insuficientemente & 1 & 20 \\
\hline Regular & 2 & 50 \\
\hline Satisfactoriamente & 3 & 60 \\
\hline Alto grado & 4 & 80 \\
\hline Plenamente & 5 & 100 \\
\hline
\end{tabular}

\section{Características de la población con proyectos en etapa de transición}

$\begin{array}{lll}\text { Género } & \text { Mujeres } & 68.75 \% \\ \text { Estrato } & \text { Hombres } & 31.3 \% \\ & 2 & 51 \% \\ & 3 & 28 \% \\ & 1 & 16 \% \\ \text { Edad } & 4 & 3 \% \\ & 5 & 1 \% \\ & 29-38 & 20 \% \\ \text { Estado Civil } & 39-48 & 20 \% \\ & 49-58 & 20 \% \\ & 18-28 & 9 \% \\ & >68 & 1 \% \\ \text { Hijos } & \text { Soltero } & 37 \% \\ & \text { Casado } & 32 \% \\ \text { Personas a cargo } & \text { Unión libre } & 14 \% \\ & \text { Viudo } & 6 \% \\ & \text { Sí } & 74 \% \\ & \text { No } & 22 \% \\ & 2 & 24 \% \\ & 2 & 22 \%\end{array}$


(Continuación). Características de la población con proyectos en etapa de transición

\begin{tabular}{|c|c|c|}
\hline & 3 & $17 \%$ \\
\hline & 0 & $15 \%$ \\
\hline \multirow[t]{2}{*}{ Cabeza de familia } & Padre & $13 \%$ \\
\hline & Madre & $31 \%$ \\
\hline \multirow[t]{5}{*}{ Población Especial } & Desplazado & $7 \%$ \\
\hline & Agricultor & $4 \%$ \\
\hline & Desplazado & $7 \%$ \\
\hline & Discapacitado & $5 \%$ \\
\hline & Afrodescendiente & $1 \%$ \\
\hline \multirow{3}{*}{ Vivienda } & Propia & $36 \%$ \\
\hline & Arriendo & $34 \%$ \\
\hline & Familiar & $29 \%$ \\
\hline \multirow{3}{*}{ Ingresos } & $<\$ 600.000$ & $68 \%$ \\
\hline & $\$ 600.000-\$ 1.800 .000$ & $6 \%$ \\
\hline & $>\$ 1 ' 800.000$ & $0.3 \%$ \\
\hline \multirow[t]{3}{*}{ Impuestos } & Sí & $32 \%$ \\
\hline & No & $33 \%$ \\
\hline & NSR & $35 \%$ \\
\hline \multirow{3}{*}{$\begin{array}{l}\text { Registro de } \\
\text { Documentación }\end{array}$} & Sí & $16 \%$ \\
\hline & Libro Contable & $16 \%$ \\
\hline & Facturación & $6 \%$ \\
\hline \multirow[t]{3}{*}{ No de Empleos } & 1 Empleo & 14 casos \\
\hline & 2 Empleos & 3 casos \\
\hline & 3 Empleos & 4 casos \\
\hline \multirow[t]{2}{*}{ Crédito } & No & $42 \%$ \\
\hline & Sí & $21 \%$ \\
\hline
\end{tabular}

\begin{tabular}{lll} 
Género & Mujeres & $66 \%$ \\
Estrato & Hombres & $34 \%$ \\
& 2 & $50 \%$ \\
& 3 & $31 \%$ \\
& 1 & $12 \%$ \\
Edad & 4 & $4 \%$ \\
& 5 & $3 \%$ \\
& $29-38$ & $24 \%$ \\
\multirow{4}{*}{ Estado civil } & $39-48$ & $20 \%$ \\
& $49-58$ & $20 \%$ \\
& $18-28$ & $1 \%$ \\
& $>68$ & $2 \%$ \\
Hijos & Soltero & $26 \%$ \\
& Casado & $39 \%$ \\
Personas a cargo & Unión libre & $22 \%$ \\
& Separado & $10 \%$ \\
& Viudo & $3 \%$ \\
& Sí & $73 \%$ \\
& No & $24 \%$ \\
& 2 & $20 \%$ \\
& 1 & $20 \%$
\end{tabular}


(Continuación). Características de la población con proyectos en etapa de transición

\begin{tabular}{|c|c|c|}
\hline & 3 & $21 \%$ \\
\hline & 0 & $17 \%$ \\
\hline \multirow[t]{2}{*}{ Cabeza de familia } & Padre & $11 \%$ \\
\hline & Madre & $18 \%$ \\
\hline \multirow{6}{*}{ Población Especial } & Desplazado & $7 \%$ \\
\hline & Agricultor & $6 \%$ \\
\hline & Desplazado & $7 \%$ \\
\hline & Discapacitado & $5 \%$ \\
\hline & Afrodescendiente & $1 \%$ \\
\hline & NA & $49 \%$ \\
\hline \multirow[t]{3}{*}{ Vivienda } & Propia & $38 \%$ \\
\hline & Arriendo & $29 \%$ \\
\hline & Familiar & $31 \%$ \\
\hline \multirow[t]{3}{*}{ Ingresos } & $<\$ 600.000$ & $42 \%$ \\
\hline & $\$ 600.000-\$ 1.800 .000$ & $48 \%$ \\
\hline & $>\$ 1^{\prime} 800.000$ & $73 \%$ \\
\hline \multirow[t]{4}{*}{ Aumento ingreso } & $>60 \%$ & $3 \%$ \\
\hline & $30 \%-40 \%$ & $17 \%$ \\
\hline & $10 \%-20 \%$ & $40 \%$ \\
\hline & $<10 \%$ & $30 \%$ \\
\hline \multirow[t]{3}{*}{ Impuestos } & Sí & $32 \%$ \\
\hline & No & $33 \%$ \\
\hline & $N S R$ & $35 \%$ \\
\hline \multirow[t]{8}{*}{ Registro docum. } & Sí & $64 \%$ \\
\hline & Libro contable & $16 \%$ \\
\hline & Facturación & $6 \%$ \\
\hline & Rut & $52 \%$ \\
\hline & INVIMA & $5 \%$ \\
\hline & sanitario & $2 \%$ \\
\hline & Marca & $5 \%$ \\
\hline & Cámara de Comercio & $21 \%$ \\
\hline \multirow[t]{2}{*}{$\mathrm{N} .^{\circ}$ de empleos } & 1 a 3 empleos & $64 \%$ \\
\hline & Casos extremos & \\
\hline \multirow[t]{3}{*}{ Crédito } & No & $42 \%$ \\
\hline & Sí & $21 \%$ \\
\hline & NRS & $37 \%$ \\
\hline \multirow[t]{3}{*}{ Activos } & Maquinaria & $37 \%$ \\
\hline & Muebles & $27 \%$ \\
\hline & Ofimática & $20 \%$ \\
\hline \multirow[t]{3}{*}{ Área laboral } & Casa & $64 \%$ \\
\hline & Local propio & $15 \%$ \\
\hline & Ambulante & $7 \%$ \\
\hline \multirow[t]{3}{*}{ Empleo } & Generan & $49 \%$ \\
\hline & No generan & $47 \%$ \\
\hline & NRS & $4 \%$ \\
\hline \multirow[t]{5}{*}{ Contratación } & Servicios & $29 \%$ \\
\hline & Labor & $27 \%$ \\
\hline & Ninguno & $40 \%$ \\
\hline & Fijo & $2 \%$ \\
\hline & Indef. & $2 \%$ \\
\hline Capacitación & Emprendimiento & $23 \%$ \\
\hline
\end{tabular}




\section{(Continuación). Características de la población con proyectos en etapa de transición}

$\begin{array}{lll} & \text { Sistemas } & 15 \% \\ & \text { Mercadeo } & 20 \% \\ & \text { Administración } & 17 \% \\ & \text { Técnica } & 14 \% \\ & \text { Financiera } & 15 \% \\ \text { Capacitación-part. } & \text { Mercadeo } & 16 \% \\ & \text { Plan } & 24 \% \\ \text { Capacitación } & \text { Mercadeo } & 20 \% \\ & \text { Contable } & 17 \% \\ \text { Mercadotecnia } & >24 \text { meses } & 37 \% \\ & 6-12 \text { meses } & 21 \% \\ & 13-24 \text { meses } & 14 \% \\ & <6 \text { Meses } & 15 \% \\ & \text { Visita } & 20 \% \\ \text { Finculación } & \text { Punto de V. } & 20 \% \\ & \text { Domicilio } & 15 \% \\ \text { Publicidad } & \text { Teléfono } & 14 \% \\ & \text { Catálogo } & 12 \% \\ & \text { Canal } & 8 \% \\ & \text { Puerta a puerta } & 6 \% \\ & \text { Fortalecimiento } & 5 \% \% \\ & \text { Creación } & 18 \% \\ & \text { Tarjetas } & 30 \% \\ & \text { Pendones } & 15 \% \\ & \text { Catálogo } & 9 \% \\ & \text { Web } & 9 \%\end{array}$

\section{Resultados}

La evaluación del impacto de las prácticas implementadas en los centros se enfoca en el nivel de participación en las actividades de desarrollo del proyecto, capacitación, comercialización y gestión documental.

La tendencia del programa registra la probabilidad en un $30 \%$ de crear 20 puestos de trabajo más en emprendimientos emergentes que en empresas establecidas (International Development Research Centre, 2014).

La población de los centros se distribuye en emprendedores, en transición y en desarrollo. El tamaño de la muestra ofrece un nivel de confianza del $90 \%$ y un error del $3.5 \%$; el tamaño de la muestra es de 552 encuestas, las cuales se distribuyen proporcionalmente para cada sede, como se muestra en la tabla 6.
Los proyectos se encuentran en etapas de desarrollo inicial y de transición.

Los centros (tabla 7) que sobresalen en el proceso Estado del Aspecto Documental también prevalecen en Informe de Gestión. Los emprendedores valoran más el sentido de oportunidad que el de preparación por preponderar más Seguimiento a Convocatorias que en los procesos de Preinscripción a Inducción y Diagnósticos. El proceso que requiere mayor atención es Diagnósticos que se relaciona con la Evaluación de Cursos.

Se puede evidenciar que los grupos con un dominio completo en Estado de Documental, Base de Datos y Planeación posibilitan mejor la Evaluación de Cursos y su Seguimiento a convocatorias. El centro numero 14 posee problemas de Inducción y Seguimiento a Convocatoria. 
Tabla 6. Población muestral

\begin{tabular}{l|c|c}
\hline \multicolumn{1}{c|}{ CEDEZO } & Encuestas & \% Muestra Total \\
\hline San Cristóbal & 105 & 19,02 \\
\hline Santo Domingo & 94 & 17,03 \\
\hline Moravia & 76 & 13,77 \\
\hline San Antonio de Prado & 70 & 12,68 \\
\hline La Quintana & 65 & 11,78 \\
\hline Santa Elena & 49 & 8,88 \\
\hline Manrique & 22 & 3,99 \\
\hline Belén & 21 & 3,80 \\
\hline La Ladera & 18 & 3,26 \\
\hline Centro & 12 & 2,17 \\
\hline Palmitas & 7 & 1,27 \\
\hline Altavista & 6 & 1,09 \\
\hline San Javier & 5 & 0,91 \\
\hline Castilla & 2 & 0,36 \\
\hline Centros comerciales & - & - \\
\hline Total & 552 & 100,00 \\
\hline Promedio & 39,43 & 7,14 \\
\hline
\end{tabular}

Fuente: estudio, 2015

Tabla 7. Seguimiento de centros

\begin{tabular}{|c|c|c|c|c|c|c|c|c|c|c|}
\hline \multicolumn{2}{|r|}{ \% Seguimiento digital y físico } & 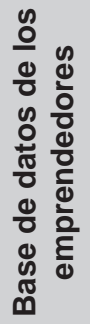 & 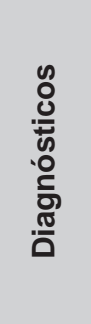 & 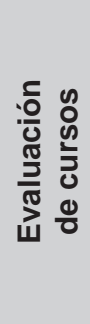 & 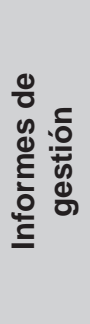 & $\begin{array}{l}\frac{0}{\pi} \\
\frac{0}{\pi} \\
\frac{\pi}{2} \\
\frac{0}{0} \\
\frac{5}{\frac{1}{0}} \\
\frac{0}{0}\end{array}$ & 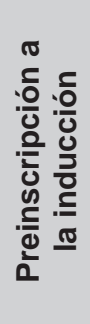 & 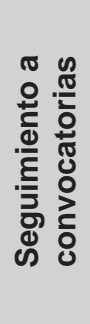 & 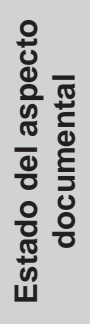 & 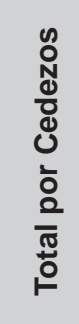 \\
\hline 1 & San Cristóbal & 72 & 20 & 20 & 76 & 72 & 20 & 20 & 55 & 44,4 \\
\hline 2 & Santo Domingo & 88 & 20 & 20 & 84 & 97 & 65 & 100 & 100 & 71,8 \\
\hline 3 & Moravia & 68 & 67 & 63 & 76 & 88 & 100 & 90 & 100 & 81,5 \\
\hline 4 & San Antonio de Prado & 88 & 60 & 60 & 75 & 84 & 85 & 96 & 100 & 81,0 \\
\hline 5 & La Quintana & 80 & 20 & 20 & 68 & 92 & 20 & 90 & 88 & 59,8 \\
\hline 6 & Santa Elena & 62 & 43 & 20 & 72 & 92 & 20 & 20 & 94 & 52,9 \\
\hline 7 & Manrique* & 83 & 98 & 90 & 80 & 80 & 80 & 72 & 98 & 85,1 \\
\hline 8 & Belén* & 85 & 100 & 100 & 100 & 92 & 100 & 100 & 80 & 94,6 \\
\hline 9 & La Ladera* & 71 & 100 & 77 & 100 & 92 & 100 & 100 & 100 & 92,5 \\
\hline 10 & Palmitas* & 78 & 20 & 20 & 76 & 52 & 0 & 0 & 89 & 41,9 \\
\hline 11 & Alta Vista* & 34 & 20 & 20 & 80 & 52 & 60 & 60 & 66 & 49,0 \\
\hline 12 & San Javier* & 68 & 20 & 63 & 92 & 80 & 80 & 60 & 98 & 70,1 \\
\hline 13 & Castilla* & 80 & 20 & 20 & 84 & 52 & 100 & 100 & 100 & 69,5 \\
\hline 14 & Centros comerciales* & 72 & 20 & 100 & 76 & 60 & 20 & 92 & 97 & 67,1 \\
\hline \multicolumn{2}{|c|}{ Total de cumplimiento por variable } & 73,5 & 44,9 & 49,5 & 81,4 & 77,5 & 60,7 & 71,4 & 90,4 & \\
\hline
\end{tabular}

Fuente: estudio, 2015 


\section{Actividades y Servicios 2005-2011 (tabla 8)}

Tabla 8. Actividades y Servicios 2005-2011

\begin{tabular}{l|r|r|r|r} 
& \multicolumn{1}{|c|}{$\mathbf{2 0 0 8}$} & $\mathbf{2 0 0 9}$ & \multicolumn{1}{c|}{$\mathbf{2 0 1 0}$} & $\mathbf{2 0 1 1}$ \\
\hline Personas capacitadas & 2.851 & 6.944 & 4.921 & 2.278 \\
\hline Horas de capacitación & 2.044 & 7.299 & 5.478 & 2.661 \\
\hline Asistentes a charlas & 3.744 & 6.341 & 7.053 & 3.479 \\
\hline Asesorías empresariales & 1.944 & 3.083 & 1.932 & 885 \\
\hline Asesorías, duración en horas & 3.657 & 3.470 & 1.493 & 744 \\
\hline Visitas a unidades productivas & & 275 & 1.058 & 502 \\
\hline Asistencia a actividades & 2.827 & 4.680 & 3.008 & 523 \\
\hline Asistencia a ofimática & & 8.307 & 10.784 & 3.688 \\
\hline Uso de portátiles en horas & & 111.011 & 24.797 & 7.763 \\
\hline Eventos comerciales & 1.131 & 278 & 392 & 58 \\
\hline Comercialización & 7.849 & 10.190 & 11.701 & 1.700 \\
\hline Sensibilizaciones & 962 & 1.901 & 1.612 & 6.501 \\
\hline Atención a red microcrédito & & 1.997 & 4.399 & 1.889 \\
\hline Asesoría de crédito Banco de lo Pobres & 392 & 944 & 1.515 & 1.889 \\
\hline Gestión interinstitucional & 16.823 & 43.615 & 48.274 & 861 \\
\hline Intervenciones en barrio & & & & 21.208 \\
\hline
\end{tabular}

Fuente: estudio, 2015

El 2011 es caracterizado por la reducción aproximada de un $50 \%$ en las actividades y servicios en los centros, el más sensible e importante de los cuales es Eventos Comerciales. Se hace necesario un seguimiento más sensible a variables que no se están registrando ni midiendo de forma correcta para explicar el descenso abrupto del requerimiento de servicios y actividades.

\section{Diagnóstico interno}

\section{Ampliación de Cobertura}

Tabla 9. Histórico de puntos de atención 2008-2011

\begin{tabular}{c|c|c|c|c}
\hline AÑO & $\mathbf{2 0 0 8}$ & $\mathbf{2 0 0 9}$ & $\mathbf{2 0 1 0}$ & $\mathbf{2 0 1 1}$ \\
\hline Cantidad & 11 & 13 & 14 & 14 \\
\hline
\end{tabular}

Fuente: estudio, 2015

\section{Capacitación y nivel de participación}

Tabla 10. Participación en procesos de capacitación

\begin{tabular}{l|c|c|c|c}
\hline \multicolumn{1}{c|}{ Temática } & $\mathbf{2 0 0 8}$ & $\mathbf{2 0 0 9}$ & $\mathbf{2 0 1 0}$ & $\mathbf{2 0 1 1}$ \\
\hline Emprendimiento & $9 \%$ & $23 \%$ & $17 \%$ & $22 \%$ \\
\hline Técnicas & $19 \%$ & $48 \%$ & $70 \%$ & $61 \%$ \\
\hline Mercadeo & $22 \%$ & $10 \%$ & $2 \%$ & $8 \%$ \\
\hline Administrativas & $36 \%$ & $8 \%$ & $8 \%$ & $4 \%$ \\
\hline Financieras & $5 \%$ & $11 \%$ & $3 \%$ & $5 \%$ \\
\hline Formalización & $9 \%$ & $0 \%$ & $0 \%$ & $0 \%$ \\
\hline
\end{tabular}

Fuente: estudio, 2015 
El incremento de horas en la capacitación posibilita la efectividad de gestión con buena cualificación logrando éxito empresarial en el mediano y largo plazo. El liderazgo de coordinadores y gestores se transfiere en las diferentes actividades de transferencia desde el 2008 con una alta aceptabilidad reflejada en la participación continua de los emprendedores (charlas empresariales, enero-junio de cada año).

Tabla 11. Participación en charlas empresariales

\begin{tabular}{|c|c|c|c|c|}
\hline Primer semestre & 2008 & 2009 & 2010 & 2011 \\
\hline Número de asistentes & 1.872 & 3.171 & 3.527 & 3.479 \\
\hline Primer semestre & 2.008 & 2.009 & 2.010 & 2.011 \\
\hline Empresas asesoradas & 972 & 1.542 & 966 & 443 \\
\hline Primer semestre & 2.008 & 2.009 & 2.010 & 2.011 \\
\hline Número de participantes & 3.925 & 5.095 & 5.851 & 6.501 \\
\hline
\end{tabular}

Fuente: estudio, 2015

En los resultados observados, sobre la gestión relacionada con las asesorías empresariales, es notable el descenso en la atención, siendo un imperativo para el proceso incorporar un presupuesto propio para apoyar el fortalecimiento de las empresas. Además, la sensibilización ha sido unas de las actividades estrella del programa y por ello se visualiza un crecimiento año tras año. Es una actividad que no debe dejar de realizarse porque los empresarios deben ser intervenidos frecuentemente para que no desfallezcan en su propósito (cada gestor logra sensibilizar en promedio 260 personas en el semestre).

En consecuencia, los centros tienen como fortaleza la capacidad de gestión, liderada por su equipo de trabajo, apalancando la red de aliados del programa para apoyar los diferentes procesos de formación y fortalecimiento de los empresarios. El número de reuniones se ha incrementado desde el 2008 hasta el 2011 en un $339 \%$, lo que permite dimensionar la credibilidad y aceptabilidad del Programa con diferentes entidades y gremios de la ciudad. Las intervenciones barriales han tenido una alta aceptabilidad por parte de los emprendedores y microempresarios de la ciudad, lo cual se ve reflejado en la gestión del capital con la creciente oferta de servicios e intervenciones barriales $(2005,41 ;$ 2008, 21808; 2011, 21208 ), atendiendo las necesidades en la que un vecino ayuda o instruye a otro en varios temas (Alcaldía de Medellín BID, 2008-2011).

La estructura organizacional es sencilla, aunque se requiere personal para la gestión de archivo y seguridad documental (Alcaldía de Medellín, 2011). El aspecto a mejorar es el de acceso por seguridad, ya que han ocurrido eventualidades en las que se suspenden los servicios por orden público. El centro n. 13 es el más eficiente, el $n .^{\circ} 12$ comparte las instalaciones con la Alcaldía lo cual representa una vulnerabilidad ante riesgos de cambios políticos en los que el programa depende de la voluntad política, además posee puntajes muy bajos en los compromisos como en los diagnóstico y Evaluación de Cursos; el centro n. 1 está por debajo del $50 \%$ del cumplimiento, pero es fuerte en Planeación, Reporte y Base de Datos; el centro $n .^{\circ} 11$ presenta baja densidad de datos e incumplimiento de dos procesos: Inducción y Seguimiento a Convocatoria, y está por debajo del $50 \%$ de cumplimiento.

Respecto al indicador de desigualdad, se encuentran cerca del $30 \%$ de los centros, mientras en el indicador de homogeneidad se halla el 24 $\%$ de los centros; en el indicador de constancia se ubica el $18 \%$ de los centros; además, el área 
Tabla 12. Puntajes fortaleza y debilidad de gestión CEDEZOS

\begin{tabular}{|c|c|c|c|}
\hline Factores críticos para el éxito & Peso & Calificación & Cumplimiento \% \\
\hline \multicolumn{4}{|l|}{ Fortalezas } \\
\hline 1. Informes de gestión & 25 & 4.5 & $90 \%$ \\
\hline 2. Evaluación de recursos & 35 & 4.0 & $80 \%$ \\
\hline 3. Plan de trabajo & 25 & 5.0 & $100 \%$ \\
\hline \multicolumn{4}{|l|}{ Promedio } \\
\hline \multicolumn{4}{|l|}{ Debilidades } \\
\hline 1. Base de datos de los emprendedores & 65 & 3.0 & $50 \%$ \\
\hline 2. Diagnósticos & 30 & 3.5 & $40 \%$ \\
\hline 3. Seguimiento a convocatorias & 25 & 4.0 & $70 \%$ \\
\hline 4. Inscripciones - sensibilizaciones & 20 & 4.0 & $70 \%$ \\
\hline 5. Estado del aspecto documental & 40 & 4.5 & $90 \%$ \\
\hline Promedio & 36,0 & 3.8 & 64,0 \\
\hline
\end{tabular}

Fuente: estudio, 2015

Tabla 13. Condiciones Ambientales y Equipos

\begin{tabular}{|c|c|c|c|c|c|c|c|c|c|}
\hline CEDEZO & $\begin{array}{c}\text { Estruc- } \\
\text { turas }\end{array}$ & Aulas & $\begin{array}{c}\text { Servi- } \\
\text { cios }\end{array}$ & Ofimática & $\begin{array}{c}\text { Mue- } \\
\text { bles }\end{array}$ & Directiva & Gestor & Vigilancia & $\%$ \\
\hline \multicolumn{10}{|l|}{ San Cristóbal } \\
\hline \multicolumn{10}{|l|}{ Santo Domingo } \\
\hline \multicolumn{10}{|l|}{ Moravia } \\
\hline \multicolumn{10}{|l|}{ San Antonio de Prado } \\
\hline \multicolumn{10}{|l|}{ La Quintana } \\
\hline \multicolumn{10}{|l|}{ Santa Elena } \\
\hline \multicolumn{10}{|l|}{ Manrique } \\
\hline \multicolumn{10}{|l|}{ Belén } \\
\hline \multicolumn{10}{|l|}{ La Ladera } \\
\hline \multicolumn{10}{|l|}{ Centro } \\
\hline \multicolumn{10}{|l|}{ Palmitas } \\
\hline \multicolumn{10}{|l|}{ Alta Vista } \\
\hline \multicolumn{10}{|l|}{ San Javier } \\
\hline \multicolumn{10}{|l|}{ Castilla } \\
\hline Centros comerciales & -- & -- & -- & -- & -- & -- & -- & -- & -- \\
\hline
\end{tabular}

Fuente: Alcaldía de Medellín, 2015

rural, con 10,94 \%, presenta mayor desigualdad que la urbana de 8,20 y desviación estándar de $8,62^{1}$. La edad de emprendimiento se concentra entre los 18 años y los 60 años.

Existen otros factores que afectan el desarrollo de los centros, entre ellos, la inasistencia (Transición, Horarios $45 \%$, falta de dinero
$26 \%$, desplazamiento $11 \%$ ) y el desarrollo efectivo de las actividades (Horarios $40 \%$, falta de dinero $5 \%$, desplazamiento $5 \%$ ), también la asociatividad (transición $7 \%$; desarrollo 24 $\%)$. En este sentido podría entenderse que se produce un fenómeno de desconfianza, el cual radicaría en la modalidad de trabajo remunerado no contratado en la que luego

1. Departamento Administrativo de Planeación. Indicador de Calidad de Vida Medellín 2004-2010. Medellín 2011. Pág. 16. 
el emprendedor no invierte en emprendedor (Endeavor Insight, 2015). Por otro lado, los ingresos (3\% salariados, $81 \%$ Actividad productiva y el $1.7 \%$ no percibe ingresos) promueven que la solución mas eficiente sea la formalización.

La variabilidad de la información suministrada por la población y los centros hacen difícil su estudio y, en consecuencia, una confiabilidad estadística, así como un respaldo documental a los libros contables como fuente primaria del estudio; ejemplo de ello es la diferencia significativa entre un emprendedor con 60 a
130 empleos y rentabilidades del $60 \%$, y otros que simplemente no ajustan sus necesidades y empresas a la formalidad impulsada por los centros, ya que la mayoría define el aumento de ingresos como una consecuencia de disminución de la deuda del negocio. En consecuencia, el sustento de validez se refiere a poseer un plan de negocio (45\%) con un contenido de altos ingresos y un grado de complejidad alto.

\section{Diagnóstico PES sobre problemas y soluciones (tabla 14)}

Tabla 14. Diagnóstico PES

\begin{tabular}{l|l}
\hline \multicolumn{1}{c|}{ Problemas } & \multicolumn{1}{c}{ Solución } \\
\hline Recurso económico & Alianza estratégica local y global en Gestión de proyectos \\
\hline Voluntad política y no política pública & Desarrollo de política mediante reglamentación \\
\hline Software como plataforma de información & $\begin{array}{l}\text { Ecosistema de emprendimiento y modelo de sistema e infor- } \\
\text { mación }\end{array}$ \\
\hline
\end{tabular}

Fuente: estudio, 2015

Visión de los emprendedores y expertos sobre la iniciativa

Tabla 15. Visión a futuro por parte de emprendedores

\begin{tabular}{l|c}
\hline \multicolumn{1}{c|}{ Problemas } & Solución \\
\hline Fortalecimiento empresarial del programa a nivel local, nacional e internacional & 10 \\
\hline Mejoramiento económico & 5 \\
\hline Eje de emprendimiento* & 5 \\
\hline Generación dinámica de empleo & 4 \\
\hline Interinstitucionalidad & 3 \\
\hline Programa como política pública & 1 \\
\hline Proteccionismo & 1 \\
\hline Formalización & 1 \\
\hline Oportunidad & 1 \\
\hline Servicio especializado & 1 \\
\hline
\end{tabular}

Fuente: estudio, 2015 
Tabla 16. Visión a futuro por parte de expertos

\begin{tabular}{|c|c|}
\hline Continuidad de proyectos y programa CEDEZO & 5 \\
\hline Interinstitucionalidad & 5 \\
\hline Cobertura & 4 \\
\hline Innovación & 3 \\
\hline Adaptación económica & 2 \\
\hline Autoaprendizaje & 2 \\
\hline Autonomía de voluntad política & 2 \\
\hline Cualificación & 2 \\
\hline Demanda & 2 \\
\hline Desarrollo & 2 \\
\hline Economía justa & 2 \\
\hline Espacio de oportunidad & 2 \\
\hline Especialización & 2 \\
\hline Herramienta de estrategia financiera y económica & 2 \\
\hline Homogeneidad & 2 \\
\hline Internacionalización & 2 \\
\hline Mejoramiento economía & 2 \\
\hline Respaldo institucional & 2 \\
\hline Desvinculación del foco económico & 1 \\
\hline Ciencia & 1 \\
\hline Tecnología & 1 \\
\hline Telecomunicaciones & 1 \\
\hline Colectivo & 1 \\
\hline Individuo & 1 \\
\hline Economía participativa & 1 \\
\hline Fortalecimiento & 1 \\
\hline Inclusión & 1 \\
\hline Acceso & 1 \\
\hline Libertad generacional & 1 \\
\hline Planeación & 1 \\
\hline Establecimiento de política pública & 1 \\
\hline Ascenso competitivo & 1 \\
\hline Formación educativo & 1 \\
\hline
\end{tabular}

Fuente: Alcaldía de Medellín, 2015 
La inter-institucionalidad requiere una mejor articulación en el proceso de planeación (Molina \& Jorge, 2015).

\section{FACTORES POLÍTICOS}

Tabla 17. Factores políticos

\begin{tabular}{|c|c|c|}
\hline ID & Factor crítico & Observación \\
\hline $\mathrm{FP}_{1}$ & $\begin{array}{l}\text { Déficit de cobertura ante } \\
\text { demanda de emprendi- } \\
\text { miento }\end{array}$ & La cobertura es progresiva y se requieren nuevas sedes \\
\hline $\mathrm{FP}_{2}$ & $\begin{array}{l}\text { Desconocimiento de la } \\
\text { normatividad relacionada } \\
\text { con la formalización y el } \\
\text { emprendimiento. }\end{array}$ & $\begin{array}{l}\text { No hay verdaderas campañas que divulguen las ventajas que ofrece } \\
\text { el gobierno nacional con respecto a la formalización empresarial; ni } \\
\text { hay medidas del orden municipal que favorezcan a los empresarios } \\
\text { que formalizan su actividad económica; ni a inversionistas, quienes } \\
\text { podrían considerar los negocios de emprendedores para hacer sus in- } \\
\text { versiones a partir de estímulos tributarios. }\end{array}$ \\
\hline $\mathrm{FP}_{3}$ & $\begin{array}{l}\text { Restricción en planeación } \\
\text { de desarrollo local }\end{array}$ & $\begin{array}{l}\text { Es evidente que el CEDEZO no participa de manera activa y decisiva } \\
\text { en la elaboración de los planes de desarrollo económicos del territorio, } \\
\text { lo cual no permite articular el proceso de crecimiento económico, de } \\
\text { acuerdo con las condiciones de cada comuna de la ciudad. }\end{array}$ \\
\hline
\end{tabular}

Fuente: Alcaldía de Medellín, 2015

FACTORES ECONÓMICOS (tabla 18)

Tabla 18. Factores económicos

\begin{tabular}{c|l|l}
\hline ID & \multicolumn{1}{|c|}{ Factor crítico } & \multicolumn{1}{c}{ Observación } \\
\hline $\mathrm{FE}_{1}$ & $\begin{array}{l}\text { Presupuesto municipal para in- } \\
\text { fraestructura }\end{array}$ & $\begin{array}{l}\text { Déficit de infraestructura y capital humano ante la demanda para } \\
\text { asesorías técnicas específicas. }\end{array}$ \\
\hline $\mathrm{FE}_{2}$ & $\begin{array}{l}\text { No hay estímulos tributarios a } \\
\text { la creación de empresas }\end{array}$ & El régimen tributario bloquea la creación de empresas \\
\hline $\mathrm{FE}_{3}$ & $\begin{array}{l}\text { Déficit financiero de apalanca- } \\
\text { miento en servicios }\end{array}$ & $\begin{array}{l}\text { Costo de gestión supera el 63\% de inversión. Los emprendedores } \\
\text { no pueden auto ni cofinanciarse. El 12\% anual de microcrédito es } \\
\text { descontextualizado a la realidad empresarial. }\end{array}$ \\
\hline $\mathrm{FE}_{4}$ & $\begin{array}{l}\text { Inexistencia de productos/ser- } \\
\text { vicios con capacidad de acce- } \\
\text { so a mercados internacionales }\end{array}$ & $\begin{array}{l}\text { La asesoría y acompañamiento técnico restringido promueve in- } \\
\text { fantilismo en el emprendimiento, lo que estanca la sofisticación de } \\
\text { productos con altos estándares de calidad. }\end{array}$ \\
\hline $\mathrm{FE}_{5}$ & $\begin{array}{l}\text { Responsabilidad social limita- } \\
\text { da }\end{array}$ & $\begin{array}{l}\text { La gran empresa, no negociar, orienta, promueve ni establece } \\
\text { alianzas empresariales con los emprendedores. }\end{array}$ \\
\hline
\end{tabular}

Fuente: Alcaldía de Medellín, 2015 
FACTORES SOCIALES (tabla 19)

Tabla 19. Factores sociales

\begin{tabular}{c|l|l}
\hline ID & \multicolumn{1}{|c|}{ Factor crítico } & \multicolumn{1}{c}{ Observación } \\
\hline $\mathrm{FS}_{1}$ & La cultura individualista & $\begin{array}{l}\text { Desconfianza de asociación, alianza y promoción de econo- } \\
\text { mía solidaria entre emprendedores }\end{array}$ \\
\hline $\mathrm{FS}_{2}$ & Inseguridad territorial & $\begin{array}{l}\text { Alto índice de asesinato, atraco, vacuna con acceso restringi- } \\
\text { do algunos CEDEZO }\end{array}$ \\
\hline $\mathrm{FS}_{3}$ & Calidad de vida & Altos niveles de desigualdad \\
\hline $\mathrm{FS}_{4}$ & Escolaridad, bachillerato completo & $\begin{array}{l}70 \% \text { Bachillerato incompleto } \\
25 \% \text { Bachillerato completo, hay un 5\% que cuentan con edu- } \\
\text { cación superior, es decir, tienen niveles inferiores, lo que hace } \\
\text { que se dificulte el proceso de aprendizaje de la creación de } \\
\text { empresas. }\end{array}$ \\
\hline
\end{tabular}

Fuente: Alcaldía de Medellín, 2015

FACTORES INSTITUCIONALES

Tabla 20. Factores institucionales

\begin{tabular}{c|l|l}
\hline ID & \multicolumn{1}{|c|}{ Factor crítico } & \multicolumn{1}{c}{ Observación } \\
\hline $\mathrm{FI}_{1}$ & Contratación temporal del talento humano & $\begin{array}{l}\text { La subcontratación genera interrupción de seguimien- } \\
\text { to de casos de emprendimiento clima laboral difícil e } \\
\text { inevitable }\end{array}$ \\
\hline $\mathrm{FI}_{2}$ & Déficit de capital humano & $\begin{array}{l}\text { Dos funcionarios y un practicante con atención a } 1.000 \\
\text { empresas }\end{array}$ \\
\hline $\mathrm{FI}_{3}$ & $\begin{array}{l}\text { Disfuncionalidad de las relaciones interna- } \\
\text { cionales }\end{array}$ & No hay proyectos de cooperación internacional \\
\hline $\mathrm{FI}_{4}$ & Gestión de la calidad limitada & Déficit de talento humano en tributaria y contable \\
\hline
\end{tabular}

Fuente: Alcaldía de Medellín, 2015

\section{FACTORES TECNOLÓGICOS}

Tabla 21. Factores políticos

\begin{tabular}{c|l|l}
\hline ID & \multicolumn{1}{|c|}{ Factor crítico } & \multicolumn{1}{c}{ Observación } \\
\hline $\mathrm{FT}_{1}$ & Centros de experimentación & $\begin{array}{l}\text { Restricción de realizar pruebas y prototipos. Remisión perdida a } \\
\text { otros lugares. }\end{array}$ \\
\hline $\mathrm{FT}_{2}$ & Renta de espacio & $\begin{array}{l}\text { Las capacitaciones implica pago espacios que no cuentan con } \\
\text { apoyo logístico ni de comunicaciones. }\end{array}$ \\
\hline $\mathrm{FT}_{3}$ & $\begin{array}{l}\text { Software que gestione el Eco- } \\
\text { sistema del emprendimiento }\end{array}$ & $\begin{array}{l}\text { La documentación está en Excel y el tamaño implica la destruc- } \\
\text { ción de datos y es desarticulado el Ecosistema del emprendi- } \\
\text { miento. }\end{array}$ \\
\hline
\end{tabular}

Fuente: Alcaldía de Medellín, 2015 


\section{FACTORES CRÍTICOS}

Tabla 22. Factores críticos

\begin{tabular}{|l|l|}
\hline $\mathrm{FP}_{1}$ & $\begin{array}{l}|c| \\
\text { Insuficiente cobertura para la atención de la } \\
\text { demanda del emprendimiento barrial. }\end{array}$ \\
\hline $\mathrm{FP}_{2}$ & $\begin{array}{l}\text { Desconocimiento de la normatividad relacio- } \\
\text { nada con la formalización y el emprendimien- } \\
\text { to empresarial. }\end{array}$ \\
\hline $\mathrm{FP}_{3}$ & $\begin{array}{l}\text { Aún el programa no participad de manera ac- } \\
\text { tiva en los planes de desarrollo locales en el } \\
\text { territorio }\end{array}$ \\
\hline & \\
\hline
\end{tabular}

\begin{tabular}{|l|l|}
\hline$F_{1}$ & \multicolumn{1}{|c|}{ Factores críticos económicos } \\
\hline $\mathrm{FE}_{2}$ & $\begin{array}{l}\text { La disponibilidad presupuestal para la alta in- } \\
\text { versión en infraestructura, en la construcción de } \\
\text { centros, depende de las finanzas municipales. } \\
\text { butarios a la creación de empresas }\end{array}$ \\
\hline $\mathrm{FE}_{3}$ & $\begin{array}{l}\text { Faltan recursos financieros para el apalanca- } \\
\text { miento de los servicios del programa. }\end{array}$ \\
\hline $\mathrm{FE}_{4}$ & $\begin{array}{l}\text { No se cuentan con productos/servicios ni ca- } \\
\text { pacidad instalada para acceder a mercados } \\
\text { internacionales. }\end{array}$ \\
\hline $\mathrm{FE}_{5}$ & $\begin{array}{l}\text { La responsabilidad social de la gran empre- } \\
\text { sa no cubre las necesidades de apoyo a los } \\
\text { emprendedores del programa. }\end{array}$ \\
\hline
\end{tabular}

\begin{tabular}{|c|l|}
\hline & \multicolumn{1}{|c|}{ Factores críticos sociales } \\
\hline $\mathrm{FS}_{1}$ & $\begin{array}{l}\text { La cultura emprendedora empresarial se } \\
\text { mantiene de manera individual dejando de } \\
\text { lado los intereses asociativos }\end{array}$ \\
\hline $\mathrm{FS}_{2}$ & $\begin{array}{l}\text { Los corregimientos no son óptimos para la } \\
\text { creación de empresa }\end{array}$ \\
\hline $\mathrm{FS}_{3}$ & $\begin{array}{l}\text { Los índices de calidad de vida de Medellín, } \\
\text { no llega a las calificaciones buenas propues- } \\
\text { tas por los estándares internacionales. }\end{array}$ \\
\hline $\mathrm{FS}_{4}$ & $\begin{array}{l}\text { El nivel de escolaridad de los emprendedo- } \\
\text { res en su mayoría está por debajo del ba- } \\
\text { chillerato. }\end{array}$ \\
\hline
\end{tabular}

\begin{tabular}{|l|l|}
\hline & \multicolumn{1}{|c|}{ Factores críticos institucionales } \\
\hline $\mathrm{FI}_{1}$ & $\begin{array}{l}\text { Falta garantía en la contratación del talento } \\
\text { humano, la cual permita continuidad a los } \\
\text { procesos del programa }\end{array}$ \\
\hline $\mathrm{FI}_{2}$ & $\begin{array}{l}\text { Insuficiente capital humano para atender los } \\
\text { beneficiarios del programa. }\end{array}$ \\
\hline $\mathrm{FI}_{3}$ & $\begin{array}{l}\text { No se han consolidado acuerdos ni conve- } \\
\text { nios con entidades del orden internacional en } \\
\text { beneficio del programa. }\end{array}$ \\
\hline $\mathrm{FI}_{4}$ & $\begin{array}{l}\text { No se tiene una proyección de mejoramiento } \\
\text { en la prestación de servicios del programa. }\end{array}$ \\
\hline
\end{tabular}

Fuente: Alcaldía de Medellín, 2015

\section{RESULTADOS DEL EJERCICIO DE ÁBACO DE REGNIER}

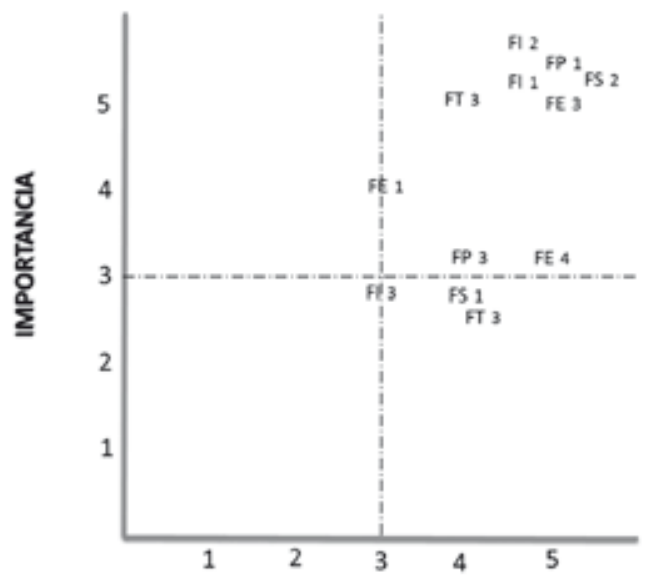

Gráfico 1. Matriz de importancia y gobernabilidad -IGO

Fuente: estudio, 2015 


\section{CONSTRUCCIÓN DE ESCENARIOS FUTU- ROS. TÉCNICA EJES DE SCHWARTZ}

Para la construcción de escenarios futuros se retoma todo el análisis anterior, con el fin de que, de manera coordinada, se definan para el largo plazo los criterios fundamentales de estos escenarios, para el programa.

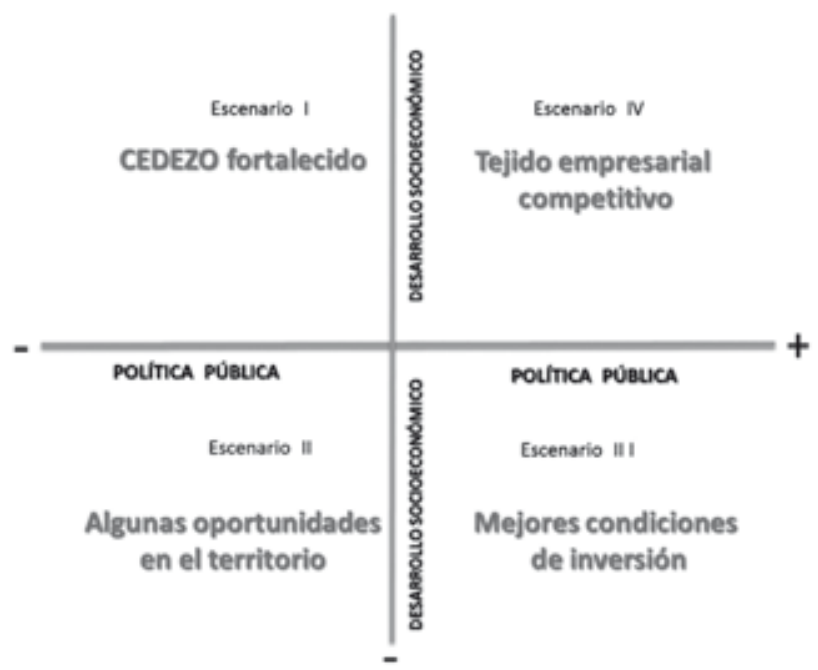

\section{Gráfico 2. Condiciones de importancia y de gobernabilidad}

Fuente: Alcaldía de Medellín, 2015

¿Qué puede ocurrir?

- La lenta desaparición del programa por descuido y debilitamiento institucional, así como la contradicción de capacitar en la generación de recursos sin poder conservar los propios, además de crear acuerdos internacionales ausentes de proyectos comunes.

- El logro de una autonomía como política de Estado de cobertura nacional, libre de la voluntad política de turno con un respaldo interinstitucional fortalecida empresarialmente, que fomente riqueza con más equidad y generación de empleo digno.

¿Qué puedo hacer?

Asistencia y cumplimiento de capacitación por parte de los emprendedores, y desde los expertos y gestores impulsar un proyecto de ley enfocado en economía solidaria.
¿Qué voy a hacer yo?

Los actores están de acuerdo en difundir el programa con una filosofía más incluyente y proteccionista, así como en generar un mejor clima de negocios entre la Gran Empresa y el Emprendedor actual.

¿Cómo voy a hacerlo?

La agremiación y la inter-institucionalidad son amenazadas por el individualismo emprendedor, así como por las malas prácticas de contratación y remuneración, y el conflicto de intereses.

El escenario I - Fortalecimiento. Indica que en la medida que se aumente el desarrollo socioeconómico (Miranda, Quintero e Higuera, 2015) con una doble alternativa de fortaleza pública y/o privada, solo se podrá sostener y mejorar el programa, lo cual implica que no se avanza en el nivel de ciudad, sino solamente con el programa, en tanto que la implementación y ejecución de acciones supere su problemática que incide regional, local e institucionalmente. 
EI escenario II- Algunas oportunidades en el territorio. A menor desarrollo socioeconómico y menor política pública, solo se logrará un nivel mínimo de mejoramiento en las comunas y corregimientos de Medellín, limitando su papel de emprendedor a un ente asesor descontextualizado y marginado que se extingue bajo expectativas y demandas insatisfechas.

El escenario III - Mejores condiciones de inversión. En la medida que solo se aumente la política pública es posible que se oriente a la parte de incentivos tributarios para los inversionistas; por lo tanto, solo se lograrán condiciones de un leve crecimiento, seguramente al nivel del PIB de la ciudad, pero no tiene grandes repercusiones en el tejido social.

EI Escenario IV - Tejido empresarial competitivo. Es el escenario que proponen los expertos, los emprendedores, los empresarios y demás actores que han participado en el estudio objeto de la consultoría. Es el que se orienta con más desarrollo socioeconómico y más política pública que favorezca el programa; se logrará el incremento de empleos, de autoempleos, mejores condiciones de ingresos, acceso a mercados tanto nacionales como internacionales, mejores posibilidades de crédito, alianzas interinstitucionales en distintos niveles, un mejoramiento en los indicadores macroeconómicos de Medellín y sus corregimientos, así como en los de calidad de vida; en fin, se podrá tener una ciudad cada vez más cercana al desarrollo, todo a partir del tejido empresarial, con el apoyo del emprendimiento del territorio.

\section{ESTRATEGIA PARA EL ESCENARIO APUESTA-TEJIDO EMPRESARIAL COMPE- TITIVO}

Tabla 23. Estrategia para el escenario apuesta de los CEDEZO

\begin{tabular}{|c|c|c|c|}
\hline Objetivo & Justificación & Meta & Responsable \\
\hline $\begin{array}{l}\text { Consolidar el progra- } \\
\text { ma como el que lidere } \\
\text { la dirección de todos } \\
\text { los procesos de desa- } \\
\text { rrollo en el territorio. }\end{array}$ & $\begin{array}{l}\text { Se requiere que el centro direccione los } \\
\text { procesos de desarrollo en el territorio } \\
\text { puesto que tiene el conocimiento de las } \\
\text { necesidades y requerimientos de las } \\
\text { empresas, los empresarios, el mercado } \\
\text { en fin todos los aspectos claves para al- } \\
\text { canzar el desarrollo. No solo esto, sino } \\
\text { que sabe del fortalecimiento social que } \\
\text { se puede ejecutar. }\end{array}$ & $\begin{array}{l}\text { Participar en un } 50 \\
\% \text { en la implemen- } \\
\text { tación de los planes } \\
\text { de desarrollo local } \\
\text { de por lo menos } 10 \\
\text { comunas de la ciu- } \\
\text { dad. }\end{array}$ & $\begin{array}{l}\text { La Alcaldía de Me- } \\
\text { dellín. } \\
\text { El comité de Plan de } \\
\text { Desarrollo de cada } \\
\text { comuna. } \\
\text { El programa. }\end{array}$ \\
\hline $\begin{array}{l}\text { Implementar un siste- } \\
\text { ma de base tecnológi- } \\
\text { ca para el ecosistema } \\
\text { del emprendimiento } \\
\text { en la ciudad. }\end{array}$ & $\begin{array}{l}\text { Es fundamental que el ecosistema del } \\
\text { emprendimiento disponga de un sis- } \\
\text { tema de información, para la monitori- } \\
\text { zación de los usuarios. Asimismo, se } \\
\text { debe disponer de un espacio donde se } \\
\text { pueda brindar un verdadero apoyo tec- } \\
\text { nológico a la demanda del emprendi- } \\
\text { miento, sin restricciones de esta índole. }\end{array}$ & $\begin{array}{l}\text { Disponer de un sis- } \\
\text { tema de información } \\
\text { en dos años para el } \\
\text { ecosistema del em- } \\
\text { prendimiento. Ad- } \\
\text { quirir tecnología de } \\
\text { alta gama para las } \\
\text { nuevas empresas, } \\
\text { en los próximos } 10 \\
\text { años. }\end{array}$ & $\begin{array}{l}\text { La Alcaldía de Me- } \\
\text { dellín. } \\
\text { La empresa privada. } \\
\text { La red interinstitucio- } \\
\text { nal. } \\
\text { El programa. }\end{array}$ \\
\hline $\begin{array}{l}\text { Realizar alianzas es- } \\
\text { tratégicas en benefi- } \\
\text { cio del tejido empre- } \\
\text { sarial de la ciudad con } \\
\text { organismos naciona- } \\
\text { les e internacionales. }\end{array}$ & $\begin{array}{l}\text { Se hace prioritario que el tejido empre- } \\
\text { sarial de Medellín y sus corregimientos } \\
\text { disponga de un portafolio amplio para } \\
\text { sus negociaciones con empresas na- } \\
\text { cionales e internacionales; asimismo } \\
\text { que pueda buscar mercados, oportu- } \\
\text { nidades y proyectos de cooperación } \\
\text { internacional para fortalecer las empre- } \\
\text { sas. }\end{array}$ & $\begin{array}{l}\text { Hacer por lo menos } \\
5 \text { alianzas y conve- } \\
\text { nios con entidades } \\
\text { nacionales e inter- } \\
\text { nacionales, en be- } \\
\text { neficio y desarrollo } \\
\text { del programa. }\end{array}$ & $\begin{array}{l}\text { La Alcaldía de Me- } \\
\text { dellín. } \\
\text { La empresa privada. } \\
\text { La red interinstitucio- } \\
\text { nal. } \\
\text { El programa. } \\
\text { El Gobierno nacio- } \\
\text { nal. }\end{array}$ \\
\hline
\end{tabular}

Fuente: investigadores, 2016 


\section{Limitaciones en la recolección de datos}

El error de la muestra: el error de muestreo está dado por el error de muestreo " $\varepsilon$ " o "aceptable" y este depende del comportamiento de la muestra, finalmente. En el estudio se convocó a un grupo de personas para que respondieran las encuestas, pero no fue posible obtener el $100 \%$ de asistencia, a pesar de haber implementado planes de contingencia para lograrlo, como, por ejemplo, varias convocatorias, atención durante varios días, durante toda la jornada a la espera de que las personas convocadas asistieran para diligenciar la encuesta. Por lo tanto, el error de la muestra aumenta a un 3.8 $\%$. Se trabaja entonces con 468 encuestas en total. Para los emprendedores en transición se aplican 291 encuestas y a los emprendedores en desarrollo se aplican 177 encuestas.

La asistencia y consejería no son posibles en el en el momento de sofisticación y crecimiento, así como la vinculación interinstitucional funcional es escasa (Bateman, Durán, \& Maclean, 2011). La micro-finanza puede convertirse en un factor desindustrializador y ser un bloqueo a la competitividad, así como favorecer un infantilismo en el emprendedor (Bateman, Durán \& Maclean, 2011).

La homogeneidad de la base se inicia en 2009, aunque existe inconsistencia en subtotales y totales entre 2005 y 2009. Las capacitaciones y los eventos de comercialización poseen trazabilidad desde 2006 a 2011. Es importante tener en cuenta que los puntos de atención comenzaron a funcionar el primer semestre de 2009 (Alcaldía de Medellín, 2011).

La gestión de archivo y documentación digital es una vulnerabilidad constante en este proyecto. No se dispone de un software para el manejo de la información que genera la dinámica de los Cedezo. Existe una base de datos que caracteriza de manera adecuada la población usuaria, pero no es factible realizar seguimiento y verificación de impactos, pues algunos son afectados por virus informáticos (Alcaldía de Medellín, 2011).

\section{Conclusiones}

La prospección del Escenario / es respaldada por los programas de las entidades públicas. En los centros se evidenció que los aspectos económicos, sociales, institucionales y tecnológicos (Ruiz \& Pérez, 2010) son las condiciones fundamentales para el desarrollo y sostenibilidad del programa, articulados con los requerimientos del talento humano.

Es importante establecer una plataforma digital para el seguimiento de casos en la gestión documental en forma actualizada y estandarizada para el registro y consulta de los participantes del programa. Los blog y usuarios en Facebook son insuficientes para la interrelación y gestión documental interinstitucional, y de la misma forma, la pérdida de tiempo en la transcripción y digitación entre hojas Excel y los manuscritos (Bernal, 2013).

Los procesos de documentación y capacitación requieren una gestión integrada para incrementar la eficacia y eficiencia del programa. Es completamente claro que el impacto positivo del programa implica su mejoramiento y continuidad en el escenario empresarial y de emprendimiento de la ciudad, de tal forma que sea altamente competitivo, de acuerdo con las exigencias internacionales; igual sucede para la implementación de procesos de innovación, investigación y tecnología.

En la medida que se potencie el CEDEZO y se convierta en el eje del desarrollo en el territorio es posible mejorar las condiciones de calidad de vida de los habitantes de la ciudad de Medellín y reportar indicadores macroeconómicos, donde el PIB se incremente, el desempleo disminuya, la balanza de pagos presente saldos positivos y así mejoren otros indicadores.

El actor autónomo, como el Banco Emisor, regula una interacción agresiva entre actores dominantes en la legislación y emprendedores, mediante formas de pago y contratación lesivas a la economía solidaria desconocida en contexto y situación (micro empresas de ANTIOQUIA, 2011), en la que los actores de enlace como los expertos expresan su voz, pero no su voto de que, al continuar esta situación, 
el programa se reduce a promover y no a emprender. La permanencia de este problema se denomina "voluntad política de turno", en la que el individualismo origina dos opuestos entre lo privado y lo público; el candidato elegido y el que viene con lo tradicional, lo nuevo y lo disfuncional, en la que se pronostica el problema y se espera a que se solucione.

Se recomienda entonces que sea el ente territorial el que dirija el fortalecimiento del tejido empresarial de la ciudad, con el apoyo de la academia, los proyectos de cooperación internacional y otras estrategias de largo plazo, de tal forma que sea posible acortar la brecha de desigualdad entre ricos y pobres mejorando las condiciones de contratación, equidad e individualismo, así como la integración de intereses de los actores del programa (Arias \& Giraldo, 2011).

\section{Referencias}

- Alcaldía de Medellín. (Abril de 2011). acimedellin. org. Recuperado el 4 de julio de 2016, de http:// www. acimedellin.org/Portals/0/Images/pdf_ publicaciones/laboratorio_medellin-aci.pdf

- Alcaldía de Medellín. (s.f.). Políticas poblacionales para una ciudad diversa e incluyente. Obtenido de https://www. medellin.gov.co/irj/go/km/docs/wpccontent/ Sites/Subportal\%20del\%20Ciudadano/ Planeaci\%C3\%B3n\%20Municipal/Secciones/ Indicadores\%20y\%20Estad\%C3\%ADsticas/ Documentos/LIBRO_PLANEACION.pdf

- Alcaldía de Medellín -BID-. (2008-2011). Transformación de una ciudad. Medellín: Multimpresos.

- $\quad$ Arias, C. \& Giraldo, D. (2011). Condiciones para la generación de emprendimientos en Medellín y su Área Metropolitana. Revista Virtual Universidad Católica del Norte, 25.

- Baena, G. (2004). Prospectiva política. Guía para su comprensión y práctica. México: Universidad Nacional Autónoma de México.

- Cámara de Comercio de Medellín para Antioquia. (2011). Home de la Cámara. Obtenido de http://www.camaramedellin.com. co/site/Portals/O/Documentos/Memorias/2011/ guia-inicio-empresarial-2011.pdf

- Concejo de Medellín. (2014). Concejo de Medellín. Recuperado el 6 de julio 2016 de http://
es.slideshare.net/ConcejoMDE/desarrolloeconmico-40875346

- Delgado, M. (2004). La política rural europea en la encrucijada. Bogotá: Ministerio de Agricultura.

- Endeavor Insight. (2015). Creando Ecosistema de Emprendimiento en el sector tech de Medellín. FOMIN. Medellín: Ruta N.

- Escalante, M. (2012). Habitabilidad en la vivienda social en edificios para población reasentada. El caso de Medellín, Colombia. Revista EURE, 38(114), recuperado de http:// www.scielo.cl. Obtenido de EURE: http://www. scielo.cl/pdf/eure/v38n114/art08.pdf

- Garcés Giraldo, L. F., \& Giraldo Zuluaga, C. (2013). El cuidado de sí y de los otros en Foucault, principio orientador para la construcción de una bioética del cuidado. Discusiones Filosóficas, 14(22), 187-201.

- Giget, M. (1998). La dynamique stratégique des entreprises. Dunod, 368.

- Giraldo, L. (4 de Julio de 2014). Propuesta metodológica para la implementación de un sistema de gestión integrado en las unidades productivas asociadas a CEDEZO. Recuperado de https://repository.upb.edu.co/bitstream/ handle/123456789/1981

- Godet, M. (1993). De la anticipación a la acción. Manual de estrategia y prospectiva. Barcelona: Marcombo

- Godet, M. (2007). Prospectiva Estratégica: Problemas y Métodos. Cuadernos de Lipsor, 104.

- International Development Research Centre. (2014). Colombian entrepeneurial dinamics. Obtenido de https://issuu.com/gemcaribbean/ docs/colombian_entrepreurial_dynamics_20

- Jouvenel, B. (1965). Futuribles. Obtenido de http://www.rand.org/content/dam/rand/pubs/ papers/2008/P3045.pdf

- Machado, D. (2014). Escenarios políticos. Para actuar en las coyunturas con pensamiento estratégico. CTA Ediciones.

- Medellín Digital-Alcaldía de Medellín. (2010). Emprendimiento Pilar de Apropiación- Medellín Digital. Recuperado el 4 de Julio de 2016, de http://cmapspublic.ihmc.us/rid=1JB4YNZ6W1JVQDS0-176N//nforme $\% 20$ final\%202010\%20 -\%20Emprendimiento.pdf

- Micro Empresas de Antioquia. (2011). Informe de Gestión de Microempresas de Antioquia Cooperativa de Ahorro Y Crédito. Medellín. MEA. 
- $\quad$ Miklos, T. (2008). Prospectiva, gobernabilidad y riesgo político: instrumentos para la acción. México: Limusa.

- Miranda, J.; Quintero, M. \& Higuera, V. (2015). Efectos del conflicto armado y el conflicto socioeconómico en el aprendizaje civilidad: La función de producción educativa en el caso del conflicto interno en Colombia. En M. López y R. Graves (Coordinadoras), Investigaciones de economía de la educación Número 10 (521-549). España: Asociación Económica de la Educación.

- Molina, C., \& Jorge, P. (2015). Un desafío de sostenibilidad: el nuevo distrito metropolitano de ciencia, tecnología, innovación y emprendimiento del valle del Aburrá en Colombia. Estudios Geográficos, 29.

- Molina, M., Vivanco, R., Silvera, A., González, M., Bracho, R. (2015). enfoque de la inclusión en la educación, significación en el contexto de los derechos humanos. En A. Silvera y O. Huertas. Derecho Penal y Educación. (75-87). Bogotá, Colombia: Sello Editorial Coruniamericana Editorial Corporación Universitaria Sabaneta Ediciones Ibáñez

- Montoya, O. (2011). Evaluación impacto de los centros de desarrollo empresarial zonal. Medellín: La Alcaldía.
- Medina, J. \& Ortegón, E. (2006). Manual de prospectiva y decisión estratégica: bases teóricas e instrumentos para América Latina y el Caribe. Santiago de Chile: CEPAL.

- Mattar, J. y Perrotti, J. (2014). Planificacion, prospectiva y gestión pública. Reflexiones para agenda de desarrollo. Santiago de Chile: CEPAL.

- Ruiz, O., \& Pérez, G. (2010). Informe final Emprendimiento 2010. Medellín: Medellín Digital.

- Salas, M. (2013). Prospectiva territorial. Una aproximación conceptual y metodológica. Venezuela: Universidad de Los Andes Venezuela.

- Silvera, A., Gómez, W., Bolívar E., Manrique, J., \& Trujillo J. (2015). Derechos humanos, convivencia y resignificación social desde la construcción de ciudad/región. En A. Silvera y O. Huertas. Derechos humanos: mujeres, libertad de expresión y multiculturalismo. (28-43). Bogotá, Colombia: Sello Editorial Coruniamericana - Editorial Corporación Universitaria Sabaneta - Ediciones Ibáñez 